\title{
Care providers' needs and perspectives on suffering and care in Bosnia and Herzegovina and Cambodia
}

\author{
Laura McDonald ${ }^{1}$, Richard F. Mollica ${ }^{1}$, Susan Douglas Kelley², Svang Tor ${ }^{1}$, \\ Majda Halilovic ${ }^{3}$
}

\author{
${ }^{1}$ Harvard Program in Refugee Trauma, \\ Massachusetts General Hospital, Boston, \\ Massachusetts, USA \\ ${ }^{2}$ Center for Evaluation and Program \\ Improvement, Vanderbilt University \\ Nashville, Tennessee, USA \\ ${ }^{3}$ Atlantic Initiative, Sarajevo \\ Bosnia and Herzegovina \\ Corresponding author: \\ Laura McDonald \\ Harvard Program in Refugee Trauma \\ Massachusetts General Hospital \\ Boston, Massachusetts, USA \\ laurasmcd@yahoo.com \\ Tel.: + 18579980116 \\ Fax.: + 16178762360
}

Received: 26 September 2012

Accepted: 16 November 2012

Copyright (C) 2012 by

Academy of Sciences and Arts

of Bosnia and Herzegovina.

E-mail for permission to publish:

amabih@anubih.ba

\begin{abstract}
This exploratory study aimed to obtain insight into field-level care providers' views on suffering and healing as well as existing obstacles and needs related to providing care to their clients. This research provides a "snapshot" for a better understanding of existing care systems in two post-conflict settings. By identifying existing approaches to care and the needs of the care provider community, this research might be useful in guiding psychosocial assistance programming in post-conflict settings. Utilizing a semi-structured questionnaire, 45 care providers were interviewed, including local health care practitioners, tradition$\mathrm{al} /$ spiritual healers, and humanitarian relief workers, in Bosnia and Herzegovina and Cambodia. This study found that the majority of care providers in both settings perceived poverty and violence as significant causes and consequences of human suffering and, at the same time, felt ill-equipped in addressing these issues and related problems. Other issues that hindered these healers in providing care included: limited government/institutional support; lack of training; material resources and funding. Study findings point to a new framework for developing effective interventions and the need for further emphasis on supporting care providers in their work, and most specifically, in identifying and responding to poverty and violence.
\end{abstract}

Key words: Traditional healing, Mental health, Psychosocial assistance, Poverty, Violence.

\section{Introduction}

Growing research reveals serious psychological distress resulting from mass violence, with the prevalence of depression in some cases being three times greater than that found among non-traumatized populations (1-3). The toll of conflict evidenced in "invisible wounds" is expected to escalate in the future (4). Currently, the devastating mental health sequelae of conflict and effective approaches to treatment are factored into the public health response in conflict-affected settings $(5,6)$.

Conflict's toll, in terms of its destruction of social and economic systems and related serious mental health outcomes of conflict, 
demands an effective response from the healing community, including local, national and international actors. The response among international organizations and non-governmental organizations to address these "invisible wounds" has been embodied in the provision of psychosocial assistance.

This area of assistance is characterized by various activities, efforts and approaches ranging from those interventions that use a trauma and individual-focused 'psychological' approach or treatment, to those that focus on strengthening community mobilization and cooperation, skills development and capacity-building (7-12). The wide variation of approaches is likely attributable to the term that describes the field itself. The term psychosocial describes and acknowledges the "dynamic relationship between psychological and social effects" that are, "continually influencing each other" (13). The overarching objectives of psychosocial interventions are to "[to both] promote existing psychosocial protective factors and minimize psychosocial stressor factors." (14).

This study aimed to obtain field-level perspectives from the care provider community, including health care providers, traditional and spiritual healers, and humanitarian relief organization (HRO) staff working in Bosnia and Herzegovina (BIH) and Cambodia. Specifically, this exploratory study aimed to obtain further insight into these care providers' views on: 1) suffering and healing and 2) existing obstacles and needs related to providing assistance. Through the lens of these providers on-the-ground, this research can provide a snapshot for a better understanding of existing care systems in two post-conflict settings. This information may be useful in guiding psychosocial assistance and approaches.

\section{Participants and methods}

The study was undertaken in Siem Reap Province, Cambodia and Travnik and Sa- rajevo Cantons, BIH. These settings were selected because they are both post-conflict environments and have received high levels of humanitarian assistance. Additionally, interviewees were readily accessible as a result of the involvement of the Harvard Program in Refugee Trauma (HPRT) in each of these settings for many years.

During the Khmer Rouge genocide in Cambodia from 1975 to 1979 , though estimates vary, an estimated 1.5 to 3 million people were killed (between $20 \%$ and $40 \%$ of the Cambodian population) $(15,16)$. Hundreds of thousands of people became refugees, with over 300,000 Khmer displaced persons living in Thailand more than a decade later (17). Under the Khmer Rouge, Siem Reap suffered one of the largest single attacks by the Khmer Rouge and mass graves have been found in the province (18-20). Fighting continued in this area up until 1997 with elements of the Khmer Rouge, with much of it occurring in the region around Siem Reap.

In 1992, violent conflict in an ethnically diverse BIH began after the referendum vote for $\mathrm{BIH}$ independence from the former Yugoslavia. The Dayton Peace Accords were signed three years later, in 1995. The total number of war deaths has been estimated at 103,000 and a total of 1.3 million were forcibly displaced, accounting for one-quarter of the country's pre-war population (21). During the war, there was heavy inter-ethnic fighting in the Travnik Canton (22). At the time of this study, BIH was widely considered a post-conflict country with significant difficulties related to the return of displaced populations to their pre-war homes.

Given the exploratory nature of this project, a semi-structured questionnaire was developed for use with study participants, to include: (1) HRO staff (local and international, working for international organizations (IOs) or non-governmental organizations (NGOs)); (2) health care providers (this classification refers to, for example, medical 
doctors, nurses, psychologists, etc.); and (3) traditional and spiritual healers. ${ }^{1}$ Consisting of 75 questions, the 90 minute interview elicited participants' views on causes and consequences of human suffering; material, psychological and social needs of clients; helping activities; and barriers to care, including training and supervision resources, job stress and burnout, and cross-sector collaboration. The interview contained both open-ended questions and Likert-scale ratings. Interviews were conducted by SDK, ST, LM and MH, with translation provided by ST and MH. Language-specific written and verbal informed consent and study procedures were approved by the Massachusetts General Hospital Institutional Review Board Human Research Committee. HPRT had several years of experience and local presence in these countries. Local HPRT staff recruited 45 participants $(22,23)$ from a list of organizations and practitioners representing each of the provider types. ${ }^{2}$ The majority of them were interviewed separately; in $\mathrm{BIH}$, two groups of two individuals from the same organization were interviewed together.

In order to analyze study data, first, we conducted a content analysis (23) of openended interview responses. Coding and analysis relied on a two-pronged content analytic approach (24) of constant comparison $(25,26)$ and grounded theory mapping $(27)$.

\footnotetext{
${ }^{1}$ Traditional healers included those who practice traditional medicine and spiritual healers comprised those individuals who are authorized to conduct worship ceremonies and perform other duties associated with their role in a religious organization. Some examples of spiritual healers include, among others, hafiz, nuns, and monks.

${ }^{2}$ Of the potential participants approached in Cambodia, two individuals refused to participate, giving reasons related to lack of time and in one case because of concerns about confidentiality based on prior experience with international research projects. In Bosnia, one individual refused to participate due to lack of time and the need to contact a parent organization for permission to participate.
}

Open-ended responses were systematically coded into four a priori categories of human functioning: social, physical, mental, and spiritual. Post hoc analyses were conducted to uncover any emergent themes, which led to the development of two additional themes of poverty and war. These were developed due to the overwhelming number of responses referring to one or both of these. Two of the authors (SDK and LM) separately coded the responses with any disagreements resolved through discussion. The resulting data are reported in terms of proportions of provider responses within each theme and specific quotes are provided to highlight relevant issues. For Likert-scale questions, answers are presented quantitatively using descriptive statistics (e.g., mean and standard deviation). Group differences between types of providers were conducted with t-tests or ANOVA's as appropriate.

\section{Results}

\section{Provider training}

In both cohorts, health care providers and HRO staff typically reported acquiring technical or clinical skills through prior related experience, formal education and degreegranting institutions, and specific training programs offered by their respective governments or other HROs. For example, a nurse in the Cambodian sample had received a nursing degree and continued training in emergency health care from an international NGO. While such training was typically supported by both institutions and governments, this participant valued her practical experience during the war more highly:

Sometimes there were not enough doctors and at the same time we had fighting. [I had to] help the patients... [There were] a lot of wounded, I had to do surgery to get bullets, sometimes amputate... learned from my experience a lot more. 
Table 1 Background characteristics by country

\begin{tabular}{lll}
\hline \multirow{2}{*}{ Characteristics } & Cambodia $(\mathrm{n}=22)$ & Bosnia and Herzegovina $(\mathrm{n}=23)$ \\
\cline { 2 - 3 } & Mean (SD) or $\%$ & 10 \\
\hline Male gender $(\mathrm{n})$ & 15 & $39.0(11.7)(25-65)$ \\
Age in years & $46.9(8.9)(27-60)$ & $91 \%$ \\
Direct care provision (face to face with clients) & $72 \%$ & $39 \%$ \\
Supervisor /Administrative responsibilities & $72 \%$ & $5.6(8.4)(0.5-38)$ \\
Number of years in position & $6.6(5.3)(1-22)$ & $11.0(9.3)(0.5-38)$ \\
Number of years in this or related field & $14.8(8.7)(3-30)$ & Majority post-graduate + \\
Education level & Varied by provider type & $61 \%$ \\
\hline
\end{tabular}

For traditional and spiritual healers, preparation often consisted of mentorship by elders or spiritual guides, which typically continued for years, often decades. For some traditional healers in Cambodia, the healing method consisted of the "guiding spirit" or proling santhita taking possession of the care provider's body; and, therefore, it was reported that no preparation was necessary for this healing method. In $\mathrm{BIH}$, several providers had received formal religious education and training.

\section{Causes of human suffering}

Participants' views on the causes and consequences of human suffering were categorized into four a priori themes of human functioning: social, physical, mental, and spiritual. As described above, upon data review, two additional themes of poverty and war were developed due to the overwhelming number of responses referring to one or both of these. Across providers in both cohorts, war- and poverty-related issues were identified as the bedrock for human suffering, most typically linked to specific social ills. Poverty, war, and social themes combined accounted for the overwhelming majority of responses by country $(95.7 \% \mathrm{BIH}$, 90.9\% Cambodia, see Table 2). As stated by an $\mathrm{HRO}$ staff member in $\mathrm{BIH}$ when asked for her views on the cause(s) of human suffering:

Poverty, definitely poverty. A lot of different reasons for it [human suffering], but everything is based on poverty. [Also] what happened during the war... [but] everything is based on poverty.

Health care providers predominantly reported poverty as a cause of human suffering, exacerbating physical health problems linked to social causes, such as a lack of education or limited access to transportation and financial resources needed to ensure timely access to health care. A health care provider in $\mathrm{BIH}$ stated that the causes of suffering are:

Poverty and war. People can't get the right treatment. For example, because of the road a patient can't get to the hospital and can't pay [when they get there].

HRO staff typically reported societal causes related to poverty and war, such as government corruption, lack of social safety or social norms, and disparity in access to education and health care. A Cambodian HRO staff commented:

...Poverty is first and human resources second. [People] are poor with no money or education...Human resources [means] people lost their trust and confidence...Before we helped each other...before the conflict, the community would help. Now it's different. 
Table 2 Causes of human suffering categorized by type of provider and theme†

\begin{tabular}{lllllll}
\hline \multirow{2}{*}{ Type of provider } & \multicolumn{2}{l}{ Themes (\%) } & & & & \\
\cline { 2 - 7 } & Poverty & War & Social & Physical & Mental & Spiritual \\
\hline Health care providers & 84.2 & 31.6 & 57.9 & 63.2 & 15.8 & 5.3 \\
Humanitarian relief organization (NGO or IO) & 46.2 & 46.2 & 76.9 & 53.8 & 38.5 & 7.7 \\
Traditional or spiritual healer & 38.5 & 53.8 & 38.5 & 46.2 & 7.7 & 38.5 \\
\hline
\end{tabular}

tPercentages may total more or less than $100 \%$ for several reasons (e.g., missing data, responses contain more than one theme).

Table 3 Consequences of human suffering by type of provider and theme

\begin{tabular}{|c|c|c|c|c|}
\hline \multirow{2}{*}{ Type of provider } & \multicolumn{4}{|c|}{ Themes (\%) } \\
\hline & Social & Physical & Mental & Spiritual \\
\hline Health care providers & 26.3 & 63.2 & 57.9 & 0 \\
\hline Humanitarian relief organization ( $\mathrm{NGO}$ or $\mathrm{IO}$ ) & 61.5 & 30.8 & 46.2 & 0 \\
\hline Traditional or spiritual healer & 23.1 & 61.5 & 53.8 & 0 \\
\hline
\end{tabular}

†Percentages may total more or less than $100 \%$ for several reasons (e.g., missing data, responses contain more than one theme).

People have lost trust and confidence. Now when we talk to [people] they say "I don't believe you".

Although human suffering related to spiritual causes was infrequently reported by other providers, traditional and spiritual healers often mentioned spiritual or religious issues in relation to physical and social causes. A BIH spiritual healer commented on the lack of faith playing a causal role in societal suffering, "a communist country...going towards disaster [and] supported something negative. A society without God had no moral values." Other traditional and spiritual healers mentioned the impact of spirits or fate as the cause of human suffering.

\section{Consequences of human suffering}

As Table 3 reveals, health care providers predominantly mentioned the physical and mental consequences of human suffering. These typically included disease, illness, and specific psychological symptoms (e.g. worry, depression, feeling unhappy, and hopelessness). The majority of HRO staff reported social and mental consequences. As an HRO staff member in BIH noted, due to societal breakdown, "communities were destroyed...[and] displacement [of people to other countries or outside their home communities] caused the breakdown of families." While traditional and spiritual healers perceived causes of human suffering as spiritual in nature, they primarily reported physical and mental consequences.

\section{Client/Patient needs}

Participants' perceptions of the clients' most significant needs and problems were grouped into four categories: (1) economic concerns (e.g., poverty, unemployment, basic needs); (2) health concerns (e.g., health problems, need for medical treatment); (3) psychological concerns (e.g., psychological symptoms and psychosomatic problems); and (4) family concerns (e.g., family support needs and family violence).

Across providers in both cohorts, client needs were congruent with the larger societal ills, poverty and war, as described above. The most frequent concerns cited were (1) economic, often linked to concerns about 
Table 4 Help for human suffering by type of provider†

\begin{tabular}{lllll}
\hline \multirow{2}{*}{ Type of provider } & \multicolumn{2}{l}{ Helping themes (\%) } & & \\
\cline { 2 - 5 } & $\begin{array}{l}\text { Supportive } \\
\text { communication }\end{array}$ & $\begin{array}{l}\text { Medical } \\
\text { treatment }\end{array}$ & $\begin{array}{l}\text { Material } \\
\text { assistance }\end{array}$ & $\begin{array}{l}\text { Spiritual/Relief } \\
\text { guidance }\end{array}$ \\
\hline $\begin{array}{l}\text { Health care providers } \\
\begin{array}{l}\text { Humanitarian relief organization } \\
\text { (NGO or IO) }\end{array}\end{array}$ & 70.6 & 66.7 & 35.3 & 0.0 \\
\begin{tabular}{l} 
Traditional or spiritual healer \\
\hline
\end{tabular} & 45.5 & 8.3 & 25.0 & 8.3 \\
\hline
\end{tabular}

tPercentages may total more or less than $100 \%$ for several reasons (e.g., missing data, responses contain more than one theme).

the future or psychological, health, and family problems. In ranking needs and problems, health care providers' responses were distributed roughly equally across categories (economic: $36.8 \%$, health: $36.8 \%$, psychological: $31.6 \%$; and family: $36.8 \%$ ).

All HRO staff mentioned clients' economic concerns (1), with fewer citing the other concerns (health: 25\%; post-conflict adaptation; psychological and family: 16.7\%). An HRO staff member in BIH stated that, "Housing, financial problems lead to emotional problems... people [who are] unemployed don't have the resources or opportunity to restore their identities." Almost one-half $(42.8 \%)$ of the traditional and spiritual healers ${ }^{1}$ reported their clients' economic concerns, while the majority $(71.4 \%)$ cited health concerns; with other categories carrying less weight, including psychological concerns $(28.6 \%)$; post-conflict adaptation (28.6\%); and family-related concerns (0\%).

\section{Assistance}

Participants' responses when asked about their beliefs about what helps people who are suffering were grouped into four themes (Table 4).

The majority of participants reported that they thought supportive communication helped people who are suffering. Gener-

\footnotetext{
${ }^{1}$ Responses for five of the 13 traditional healers and spiritual/religious leaders could not be coded due to missing data or unclear statements.
}

ally, mental health providers (e.g., classified in this study as health care providers) mentioned more formalized communication, such as counseling. Others reported more informal communication through talking, listening, or providing education (e.g., on appropriate medical care). A care provider in BIH noted the importance of listening in helping someone feel "supported and [able] to talk openly." An HRO staff in Cambodia stated that it is important to "find out why the patient thinks they are suffering, to provide options."

Secondary to supportive communication, helping themes were associated with provider type. Health care providers were more likely to mention medical treatment, such as medical care or referral. The majority of traditional and spiritual healers reported spiritual and religious guidance, such as preaching and using specific spiritual practices. HRO staff primarily reported material assistance as a helping theme.

\section{Barriers to care}

Information provided by participants on existing barriers to effectiveness was categorized into themes: lack of (1) institutional/ governmental support, (2) physical support (e.g. resources, tools, and infrastructure); (3) knowledge, training, and (in some cases) insufficient supervision; (4) community stigma; and (5) the need for continued donor funding. Self-care and burnout issues 
(6) were also revealed. Across providers in both countries, $65 \%$ of responses pertained to the themes (1) (2) and (3).

Many health care providers in BIH reported that the lack of institutional support (1) contributed to employee frustration and negatively impacted their ability to provide clinical care. Several health care providers in Cambodia noted the lack of physical support (2), mentioning the lack of resources for free medical care and the need for updated medical equipment and supplies.

Lack of knowledge and training, including both education prior to taking a position and ongoing training, were also frequently cited as there were some limitations in supervision (3). The majority of participants, in both cohorts, mentioned the general need for continuing position-related training relevant to their positions. A lack of resources (including institutional awareness and financial) for training was often reported.

Clinical skill deficits were mentioned by the majority of health care providers and some traditional healers, focusing on the need for updated training and materials. All international HRO staff $(\mathrm{N}=3)$ reported prior training in cultural issues with a need for more intensive language training. Equal numbers of traditional healers and health care providers commented on the need for basic training in the identification and treatment of mental health disorders.

One health care provider stated:

I don't know how to help patients [with mental health needs]. It's very good to learn about psychiatric diagnoses. [For example] patients with malaria have the same symptoms as depression. Some patients...get cured [with malaria treatment] but some have symptoms still there that need to be diagnosed, but I don't know how.

Regular supervision was reported for all health care providers and HRO staff in Cambodia and in $\mathrm{BIH}$, supervision was reported for $86 \%$ of HRO staff and $50 \%$ of health care providers. Supervision was reported to a lesser extent among traditional and spiritual healers. Several health care providers noted that supervision had occurred previously, and frequently associated this with the work of outside/international HROs. Many reported that formal supervision had ceased to exist when the involvement of International HROs ended. A BIH HRO staff member expressed that it "would be useful to have a supervisor but we can't afford it."

The impact of community stigma (4) on program effectiveness was mentioned by $13 \%$ of participants. Such stigma was typically associated with mental health and some physical health problems (e.g., HIV infection). A number of care providers implied that there was stigma surrounding their use. Donor funding issues, including adequacy and the need for continued support (5), were mentioned by $10 \%$ of HRO staff. An HRO staff person in Cambodia stated that, "equipment will deteriorate because foreign staff can access outside funding...the knowledge [from training] will stay."

This study's findings with regards to job stress and burnout (6) were limited, with several participants reporting no job stress or personal problems. Findings may have been influenced by cultural context (e.g., in Cambodia, for example, it is not generally acceptable to discuss one's own problems openly). Participants did, however, report several job-related stressors, including feeling overwhelmed by client needs or the amount of work. An HRO staff member in Cambodia noted often feeling "frustrated because he couldn't do more due to limited time and resources." While in $\mathrm{BIH}$, an HRO staff member reported "being close to burnout...I got sick, tired, irritable, [it was] hard to concentrate, I couldn't listen." Job stress was reported to impact work performance, with providers reporting changes in attitude towards work and anger towards other staff. Activities that helped with job stress includ- 
Table 5 Collaboration by type of provider

\begin{tabular}{|c|c|c|c|c|}
\hline \multirow{3}{*}{ Sector } & \multicolumn{4}{|c|}{ Type of provider (Respondent to survey) $\dagger$} \\
\hline & Health & HRO & TH/Spir & \\
\hline & Mean (SD) & Mean (SD) & Mean (SD) & $\mathrm{F}$ \\
\hline Other HRO & $2.9(1.3)$ & $4.3(0.9)$ & $2.0(1.5)$ & $8.39^{* *}$ \\
\hline Health care & $3.6(1.5)$ & $4.0(1.0)$ & $2.4(1.6)$ & $3.49 *$ \\
\hline Traditional healers & $1.3(0.8)$ & $1.6(0.8)$ & $2.0(1.6)$ & 1.38 \\
\hline Spir./Rel. leaders & $1.7(1.1)$ & $2.1(1.0)$ & $2.3(1.8)$ & 0.79 \\
\hline Community leaders & $2.4(1.2)$ & $4.1(0.9)$ & $1.8(1.4)$ & $11.27^{* * *}$ \\
\hline Schools/Teachers & $3.6(1.6)$ & $4.0(1.0)$ & $1.8(1.6)$ & $6.71 * *$ \\
\hline
\end{tabular}

†Health = Health care providers; HRO = Humanitarian relief organization (NGO or IO); $\mathrm{TH} / \mathrm{Spir}=$ Traditional or Spiritual healer). ${ }^{*} \mathrm{p}<0.05$; ${ }^{* *} p<0.01 ;{ }^{* *} p<0.001$. There were 2 degrees of freedom for all between groups ANOVAs.

ed talking with others (co-workers, family, and friends), taking time to rest and relax, engaging in social and spiritual activities, and exercise.

\section{Collaboration}

HRO staff reported a higher level of collaboration across sectors than either health care providers or traditional and spiritual healers. Post hoc analyses were conducted using the Bonferroni correction for multiple tests. According to their report, HRO staff collaborated more with other HRO staff than did health care providers (mean difference $=1.3$, $\mathrm{p}<0.05)$ and traditional and spiritual healers (mean difference $=2.3, \mathrm{p}<0.001$ ). The results were similar for collaboration with community leaders, with higher rates for HRO staff than health care providers (mean difference $=$ 1.7, $\mathrm{p}<0.01$ ) and traditional and spiritual healers (mean difference $=2.3, \mathrm{p}<0.001$ ). There were no significant differences in collaboration with either sector for health care providers and traditional and spiritual healers.

Ratings of collaboration with the health care sector were high for health care providers and HRO staff, with HRO staff indicating significantly more collaboration than traditional and spiritual healers (mean difference $=1.6, \mathrm{p}<0.5)$. It is interesting to note that this could be interpreted as health care providers perceiving less collaboration with HRO than the HRO themselves. There was no difference in collaboration between health care providers and traditional and spiritual healers. Per report, traditional and spiritual healers collaborated less with schools and teachers than did health care providers (mean difference $=1.85, \mathrm{p}<0.05$ ) and HRO staff (mean difference $=2.3$, $\mathrm{p}<0.01$ ). No group collaborated significantly with traditional and spiritual healers.

Collaboration with traditional and spiritual healers is limited, and this group has the lowest rates of collaboration across sectors. A spiritual leader in Cambodia indicated role constraint impacting collaboration, stating "people come to me for help; as a monk, I can't do anything more than that." However, a traditional healer in Cambodia noted the value of indigenous healers, stating that, "traditional healers are [most] community oriented, [fitting within] the cultural structure." A health care provider in $\mathrm{BIH}$ reported no direct collaboration with traditional healers, but that, "we know the client goes and will support them in going."

Several providers in $\mathrm{BIH}$ commented on organizational, personal, or cultural issues that impacted collaboration. A health care provider reported some cooperation with other sectors, but stated that there, "should be better cooperation, but it's not our fault 
or theirs...just a problem in organization." A spiritual healer noted some collaboration with HRO in the past, but that "humanitarian aid provided all the time might make [clients] lazy." Speaking about collaboration with the health care sector, an HRO staff stated:

They are increasingly turning to [us]. At first they thought we were interfering foreigners. Now they realize we are on their side, that we have qualifications and something to say.

\section{Discussion}

This study provides a microcosm of healing communities in two different post-conflict settings from the viewpoint of field-level care providers. Both the study approach and its findings provide some useful guidance for psychosocial assistance approaches and activities.

\section{Listening to the voices of care provider community}

This research demonstrates the value of eliciting the input of the care provider community to better understand the context, current approaches, and needs of care providers and the larger community in post-conflict settings. We believe that this type of exploratory research might be a useful approach/ tool in guiding and negotiating a response between affected communities and outside agencies that aim to provide psychosocial assistance. While psychosocial assistance activities aim to acknowledge the experience, knowledge, capacity and contribution of local providers in the post-conflict setting and avoid depleting mainstream services, this provides a concrete framework for eliciting and analyzing community input to guide program decisions and negotiations between the war-affected community and outside agencies. This type of exploratory research might be included as a cen- tral component in the planning and design phases for psychosocial assistance programs in post-conflict settings.

This study highlights the centrality of poverty and violence as areas responsible for suffering where support is needed, and we would expect these social ills to be highlighted in other post-conflict settings (which are also often characterized by high levels of poverty and violence). However, the support the care providers need in addressing these issues might be different and/or other social issues might also emerge through this exploratory research. This research and rich data obtained from care providers can provide the basis of an action plan for the care provider and social service community. Not only does such an approach reflect sensitivity to local capacities, approaches, and needs, but it also gives local communities their rightful role as key players in post-war recovery and rehabilitation (28).

\section{Poverty and violence in $\mathrm{BIH}$ and Cambodia}

Study findings also provide some evidence that additional support in addressing issues related to poverty and violence might be useful in post-conflict settings, to promote and improve the psychosocial care of war-affected populations. Given its broad mandate, addressing both psychological and social issues, the field of psychosocial assistance is well-placed to respond to this identified need for support. Concrete guidance in addressing these specific issues through psychosocial assistance is needed. While additional social issues might be identified in other settings, we believe that specific support in these two areas should be further considered in psychosocial assistance programming. This viewpoint is based not only the prevalence of poverty and violence in these settings, but also on a growing body of research which shows interlinkages be- 
tween poverty, violence and mental health outcomes (29-31).

\section{Integrative and collaborative care systems are needed}

The multi-dimensional experience and impact of poverty and violence warrants further consideration in psychosocial assistance, and highlights the need for activities which support an integrated healing system. Some manifestations of poverty and violence include, for example, child abuse, domestic violence, substance dependence and crime, other high risk activities and poor health (32-35). Therefore, it might be useful in post-conflict settings to strengthen linkages among local care providers themselves and between local care providers and the larger social service system. For example, a network could be established linking care providers to services such as child care, training in parenting and self-protection, substance use prevention activities, skills training, supported employment, and other efforts to support socio-economic integration, etc. While various approaches to healing, such as supportive communication, are viewed as helpful, their effectiveness is further strengthened with the provision of concrete social assistance. One important issue raised by care providers in BIH was a lack of adequate housing, yet neither health care providers nor HROs reported assisting with housing needs. Though they may not be responsible for providing housing, they should be able to facilitate and guide clients towards accessing assistance to meet this need.

An integrated approach would be particularly useful in settings where, for example, mental health care is highly stigmatized. It can also play an important role in reducing duplication of services. Within a collaborative and integrated care system, an individual's various needs can be met regardless of where they enter the care system. Any effec- tive system must also consider a community's reliance on and the role of spiritual and/ or traditional healers in healing activities and care (36-37) and ensure their linkages to the larger care system.

\section{Resources and capacity-building}

This analysis provided evidence that training for local care providers in $\mathrm{BIH}$ and Cambodia in addressing poverty and violence might be useful. This is not surprising as, for example, research has found that mental health issues often go unnoticed in the primary care setting. Research shows that training programs have been effective in increasing the capacity of health care workers to identify and address issues related to mental health, and other outcomes associated with poverty and violence (38-44).

In this setting, it is not surprising that limited access to resources and support was cited as a barrier to providing effective care as was training, more generally. Care providers indicated that they needed training in supervision, languages, and in writing. Further, training in specific areas of care might be warranted. For example, most care providers did not have confidence in addressing substance abuse/dependence issues. In addition, awareness-raising and training selfcare might be useful in improving the care provider community's capacity to provide adequate care to their clients while protecting their own health and well-being.

\section{Emphasizing evidence-based practice}

Since this research was undertaken, significant strides have been made in developing the evidence base for psychosocial assistance activities and approaches. Further, a number of resources have been collaboratively developed, including, for example, the Inter-Agency Standing Committee on Mental Health and Psychosocial Support in 
Emergency Settings (45) to guide efforts and approaches in psychosocial care. The field should continue to focus on building the research base, documenting promising practices and continue to promote and set guidelines related to standards of care. This is not just adding to the 'toolbox' of psychosocial interventions, but calls for thinking 'outside the box' in terms of identifying and designing interventions and measuring their impact. One example of this might be providing people with opportunities to help others, as there is evidence that giving people the opportunity to practice altruistic behavior is associated with better mental health outcomes (46). Over time, this is an important way that resources for such assistance can be secured - a particular concern, as found in this study, and more generally today in the context of limited and competing resources in post-conflict settings. Further, while the community can provide important guidance and insight into areas where assistance would be useful, practitioners in this field can also provide important useful information and guidance on the basis of evidencebased approaches that have been effective in other settings.

\section{Limitations of study}

This study provided important insight into psychosocial practices and field-level realities in two post-conflict environments from the prospective of the care provider community. There are some limitations, including the study's small sample size and the absence of interviews with all types of relief providers (e.g., development organizations) and clients. Information from clients, and other important providers (e.g., human rights, advocacy and protection sector actors), would provide important insights into this study's findings, as well as into the utility and feasibility of its recommendations. Finally, these data were collected in 2003 and, therefore, may not perfectly reflect practice today. However, it is our view that the central tenets of the paper and study findings remain useful and valid today.

\section{Conclusion}

Effective approaches to healing and capacity for providing such care are already present in post-conflict settings, though they may have been damaged during conflict. A systematic effort to listen to the field-level care providers' "voices" can provide important insight into their capacities and needs, in turn guiding psychosocial programming. This approach reflects the central tenets of relief and development assistance, to ensure that activities to assist communities are informed and guided by the communities themselves. On this basis, the psychosocial field is well placed to ensure effective care is provided to address both psychological and social needs.

Authors' contributions: Conception and design: LM, RM, SDK, ST; Acquisition, analysis and interpretation of data: LM, RM, SDK, ST, MH; Drafting the article: LM, SDK, RM; Revising it critically for important intellectual content: LM, SDK.

Acknowledgements: Funding provided through a grant from the Andrew W. Mellon Foundation to the Harvard Program in Refugee Trauma (1999). Partial support for Dr. Kelley provided by a W.T. Grant Fellowship through the Harvard Children's Initiative. The data presented, the statements made, and the views expressed are solely the responsibility of the authors.

Conflict of interest: The authors declare that they have no conflict of interest. This article was not sponsored by any external organisation.

\section{References}

1. Robins L, Reigier D, editors. Psychiatric disorders in America: The Epidemiologic Catchment Area Study. New York: The Free Press; 1991.

2. Norris FH, Byrne CM, Diaz E, Kaniasty K. The range, magnitude, and duration of effects of natural and human-caused disasters: a review of the empirical literature. National Center for Post- 
Traumatic Stress Disorder, Department of Veterans Affairs; 2001.

3. Roberts B, Damundu EY, Lomoro O, Sondorp, E. Post-conflict mental health needs: a cross-sectional survey of trauma, depression and associated factors in Juba, Southern Sudan. BMC Psychiatry. 2009;4(9):7.

4. Mollica RF. Invisible Wounds. Sci Am. 2000;282(6):54-7.

5. Waldman R, Martone G. Public Health and Complex Emergencies: New Issues, New Conditions. Am J of Public Health. 1999;89(10):1483-5.

6. Mollica RF, Lopes Cardozo B, Osofsky HJ, Raphael B, Salama P. Mental health in complex emergencies. The Lancet. 2004;364(9450):2058-67.

7. Ager A. Tensions in the psychosocial discourse: Implications for the planning of interventions with war-affected populations. Dev Pract. 1997;7(4):402-7.

8. Summerfield D. Assisting survivors of war and atrocity: Notes on 'psychosocial' issues for NGO workers. Dev Pract. 1995;5(4):352-60.

9. Summerfield D. A critique of seven assumptions behind psychological trauma programmes in waraffected areas. Soc Sci Med. 1999;48:1449-62.

10. Bracken P, Giller JE, Summerfield D. Rethinking Mental Health Work with Survivors of Wartime Violence and Refugees. Journal of Refugee Studies. 1997;10:4431-42.

11. Population Council. Psychosocial benefits of a mentoring program for youth-headed households in Rwanda. 2007. Found November 13, 2012 from: http://www.popcouncil.org/pdfs/horizons/RwandaPsychOVCImpactSum.pdf

12. McDonald L. Psychosocial Rehabilitation of Civilians in Conflict-Affected Settings (Chapter 10). In Martz E, editor. Trauma Rehabilitation after War and Conflict. New York: Springer; 2010.

13. Policy guidelines on the psychosocial care and protection of children in armed conflict: Recommendations. Nairobi, Kenya. UNICEF; 1997.

14. Arts PGH. Draft guidelines for programmes: Psychosocial and mental health care assistance in (post) disaster and conflict areas. Netherlands Institute for Care and Welfare; 2001.

15. Kiljunen K. Power politics and the tragedy of Kampuchea during the seventies. Bull Concern Asian Sch. 1985:1749-64.

16. Hannum H. International law and Cambodian genocide: the sounds of silence. Hum Rights Q. 1980;11:82-138.

17. Mollica RF, Jalbert RR. Community of confinement: The mental health crisis in Site Two (Displaced persons camps on the Thai-Kampuchean border). Report for the Committee on Refugees and Migrants, World Federation for Mental Health; 1989.

18. Duffy T. Toward a Culture of Human Rights in Cambodia. Human Rights Quarterly. 1994:16(1);82-104

19. Reuters. Mass grave found in Cambodian village. August 7, 2012. Found on November 13, 2012 at: http:// www.reuters.com/video/2012/08/07/mass-gravefound-in-cambodian-village? videoId $=236903252$

20. Yale University. Cambodian Genocide Program. Provincial Killing Fields: Director for province links. (Map) Found November 13, 2012 at http:// www.yale.edu/cgp/maps/directory.html

21. Cain J, Duran A, Fortis A, Jakubowski E. In Cain J, Jakubowski E, editors. Heath care systems in transition: Bosnia and Herzegovina. Copenhagen: European Observatory on Health Care Systems; 2002.

22. CESPI (Centro Studi di Politica Internazionale). Local Democratic Governance in Travnik Municipality. First Report. SeeNet Programme; 2010.

23. Bazeley P. Computerized data analysis for mixed methods research. In Tashakkori A, Teddlie C, editors. Handbook of mixed methods in social and behavioral research. Thousand Oaks, CA: Sage; 2003.

24. Holsti OR. Content analysis for the social sciences and humanities. Reading, MA: Addison-Wesley; 1969.

25. Glasser B, Strauss A. Discovery of grounded theory: Strategies for qualitative research. Chicago: Adeline; 1967.

26. Charmaz K. Reconstructing grounded theory. In Alasuutari P, Bickman L, Brannen J, editors. The SAGE handbook of social research methods. Los Angeles: Sage; 2008. p. 461-78.

27. Clarke AE. Situational analyses: Grounded theory mapping after the postmodern turn. Symbolic Interaction. 2003;26:553-76.

28. Mollica RF, McDonald L. Refugees and mental health: Old stereotypes, new realities. UN Chronicle. 2002;39(2):29-30.

29. Patel V, Araya R, de Lima M, Ludermir A, Todd C. Women poverty and common mental disorders in four restructuring societies. Soc Sci Med. 1999;49:1461-71.

30. Costello EJ, Compton SN, Keeler G, Angold A. Relationships between poverty and psychopathology: a natural experiment. JAMA. 2003;290;2023-9.

31. Roberts GL, Williams GM, Lawrence JM, Raphael B. How does domestic violence affect women's mental health? Wom Health. 1998;28(1):117-29. 
32. Djeddah C, Facchin P, Ranzato C, Romer C. Child abuse: Current problems and key public health challenges. Soc Sci Med. 2000;51(6):905-15.

33. Oyemade A. Child abuse and neglect: A global phenomenon. African Journal of Medicine and Medical Sciences. 1991;20(1):5-9.

34. Huch MH. Violence against women: a worldwide problem. Nur Sci Q. 2000;13(4):339-40.

35. Armstrong TD, Costello EJ. Community studies on adolescent substance use, abuse, or dependence and psychiatric comorbidity. Journal of Consulting and Clinical Psychology. 2002;70(6):1224-39.

36. Kayombo EJ, Mbwambo ZH, Massila M. Role of traditional healers in psychosocial support in caring for the orphans: A case of Dar-es Salaam City, Tanzania. Journal of Ethnobiology and Ethnomedicine. 2005;1-3.

37. Ngoma MC, Prince M, Mann A. Common Mental disorders among those attending primary health clinics and traditional healers in urban Tanzania. Br J Psychiatry. 2003;183:349-55.

38. World Health Organisation (WHO). World Report on Violence and Health. Geneva: WHO; 2002.

39. Domestic Violence: A Resource Manual for Health Care Professionals. Chapter 5: Education and Training. Cardiff: The National Assembly for Wales; 2001.
40. World Health Organisation (WHO). The World Health Report 2001: Mental Health: New Understanding, New Hope. Geneva: WHO; 2001.

41. World Health Organisation (WHO). Diagnosis and Management of Common Mental health disorders in primary health care. Geneva: WHO; 1998.

42. Day A, Thurlow K, Woolliscroft J. Working with childhood sexual abuse: a survey of mental health professionals. Child Abuse Negl. 2003;27:191-8.

43. Henderson, DC, Mollica RF, Tor S, Lavelle J, Hayden, D. Building primary care practitioners' confidence in mental health skills in a post-conflict society: a Cambodian example. J Nerv Ment Dis. 2005;193(8):551-9.

44. Bower P, Garralda E, Kramer T, Harrington R, Sibbald B. The Treatment of child and adolescent mental health problems in primary care: a systematic review. Fam Pract. 2001;18:373-82.

45. Inter-agency Standing Committee. IASC Guidelines on mental health and psychosocial support in emergency settings. Geneva: IASC. 2007. Found November 12, 2012 at: http://www.who. int/hac/network/interagency/news/iasc_guidelines_mental_health_psychososial.pdf

46. Mollica, RF, Cui X, McInnes K, Massagli MP. Science-based policy for psychosocial interventions in refugee camps: a Cambodian example. J Nerv Ment Dis. 2002;190:158-66. 